\title{
Implementation of UPFC for Improvement of Power Stability
}

\author{
Savinder Malik ${ }^{1}$, Lalit Dalal ${ }^{2}$, \\ Research Scholar ${ }^{1}$, Research Scholar ${ }^{2}$ \\ GITAM, Kablana, Jhajjar, Haryana, India-124104,
}

\begin{abstract}
The focus of this research work is on a FACTS device known as Unified Power Flow Controller $(U P F C)$, which can provide simultaneous control of basic power system parameters like voltage, active power flow, reactive power flow, impedance and phase angle. In this research work, simulation models for different multi machine systems are carried out, e.g. a hybrid power system, a power system with two synchronized hydro power stations etc., without UPFC \& with UPFC located at the load end of the power system, has been developed. Simulation models have been incorporated into MATLAB based Power System Toolbox (PST) for their voltage stability analysis. These models were analyzed for voltage, active power flow, and reactive power flow and phase angle, with and without UPFC. The results of the power system with UPFC and without UPFC are compared and the conclusion is given at the end.
\end{abstract}

Keywords: UPFC, FACTS, PST

\section{Introduction}

In today's high complex and interconnected power systems, there is a great need to improve power utilization while still maintaining reliability and security. Reducing the effective reactance of lines by series compensation is a direct approach to increase transmission capability. However, a power transfer capability of long transmission line is limited by stability consideration [13]. Oscillation of generator angle or line angle are generally associated with the transmission system disturbances and can occur due to step changes in load, sudden change of generator output, transmission line switching and short circuit [18]. Different modes of rotor oscillation are local mode, intra-area mode and inter-area mode. The frequency of oscillations of rotor swings varies from 0.2 to $4 \mathrm{~Hz}$ [2]. The lower end of frequency spectrum corresponds to inter-area modes, in which a large number of generators participated and their damping is difficult. This low frequency is important to damp as quickly as possible because they cause mechanical wear in power plants and cause power quality problem. If the electromechanical oscillations are not properly controlled in the electric power system operation, it may lead to a partial or total system outage [18]. Instability problems in power systems that can lead to partial or full blackout can be broadly classified into three main categories, namely voltage, phase angle and frequency related problems [3]. In early age this signal instability problem was solved by amortisseurs implemented in generator rotors, later with the application of fast excitation system this was solved by development \& utilization of Power System Stabilizer (PSS) and however in modern power system due to the connection of power grids in vast area, for inter area oscillation damping due to the ability of controlling line impedance, power flow and bus voltage, Flexible AC transmission Systems (FACTS) devices implementation offers an alternative solution [19].

\section{Case-With Two Hydro Generating Stations}

1) Under 3-Phase to Ground Fault Condition without FACTS Devices 

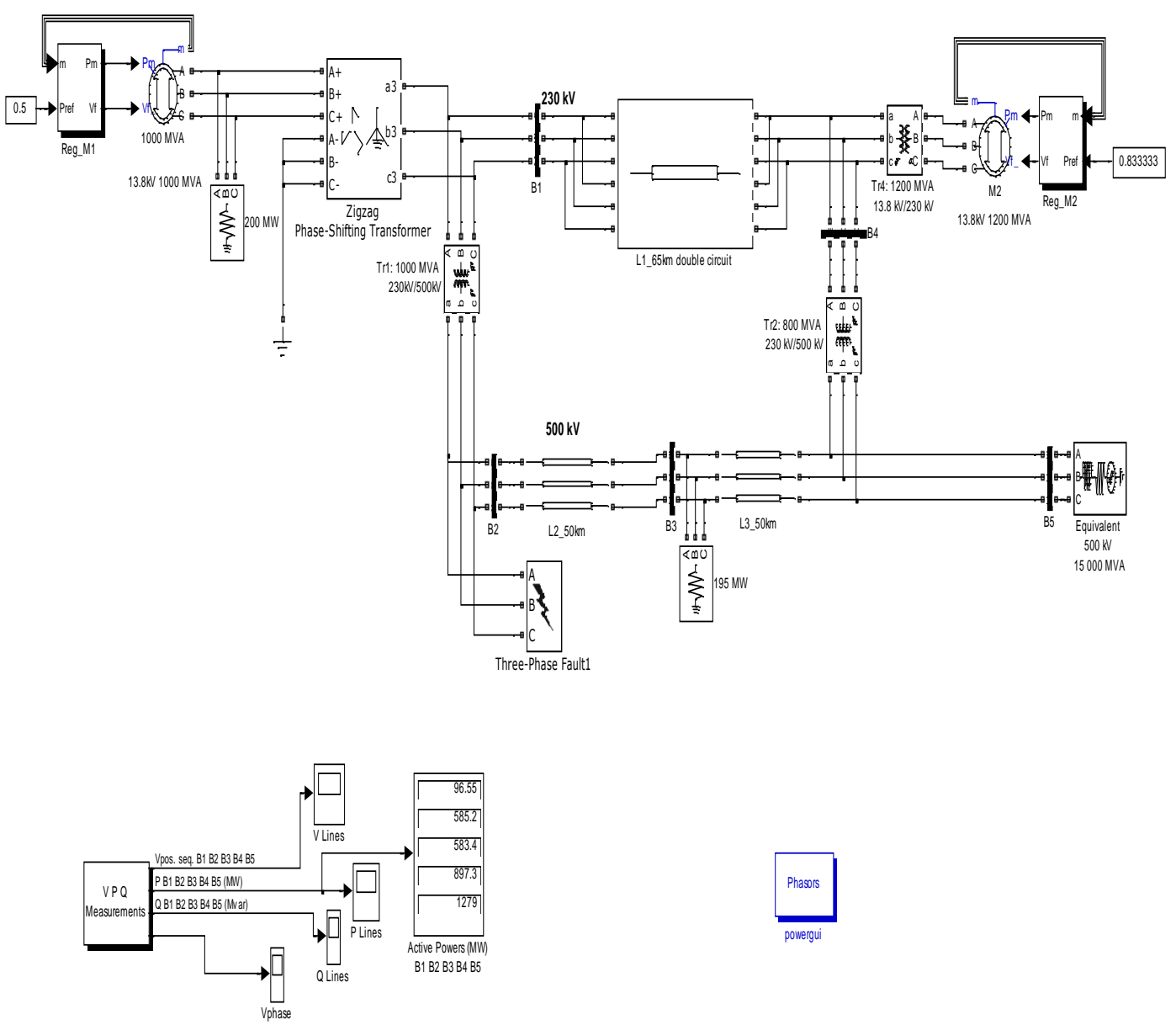

Fig.1 Two Hydro Generating Stations Under 3-Phase to Ground Fault Condition

A three phase to ground fault is created at $\mathrm{t}=10 \mathrm{sec}$ for $0.08 \mathrm{sec}$ at bus 2 as shown in fig. 1 . The active power, reactive power, voltage and phase angle curves with respect to time at different buses (B1 B2 B3 B4 B5) are shown in fig. 1.1.1-1.1.8

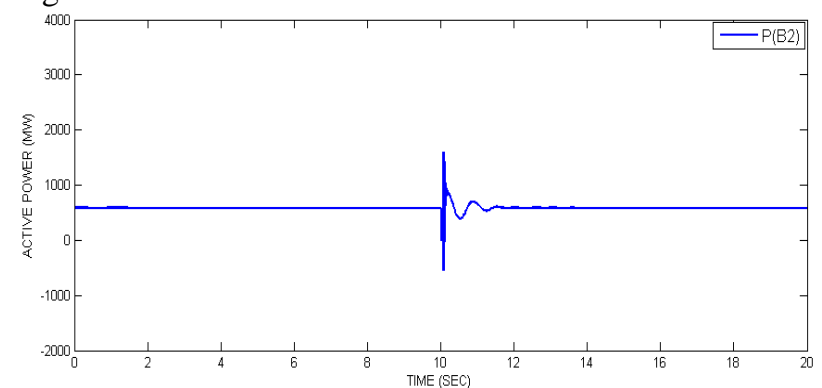

Fig 1.1 Active Power At Bus B2

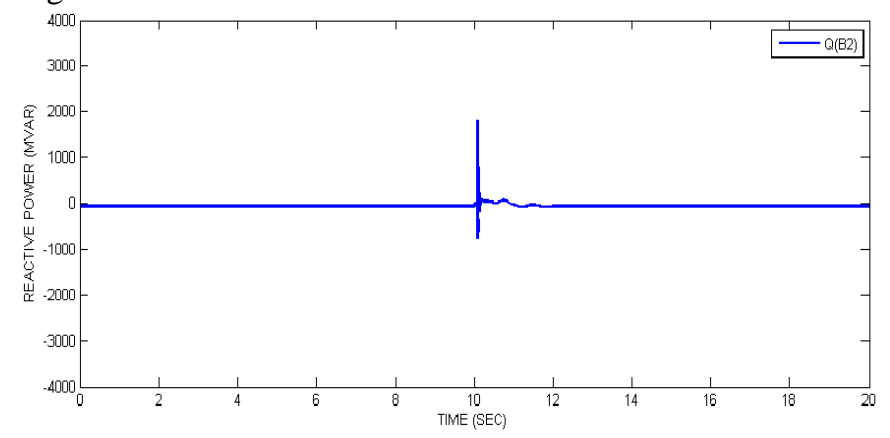

Fig. 1.2 Reactive Power At Bus B2 


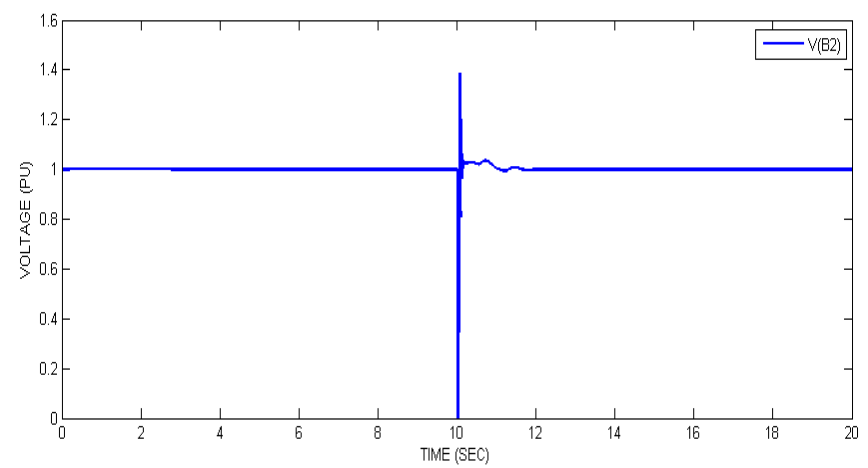

Fig. 1.3 Voltage Bus B2

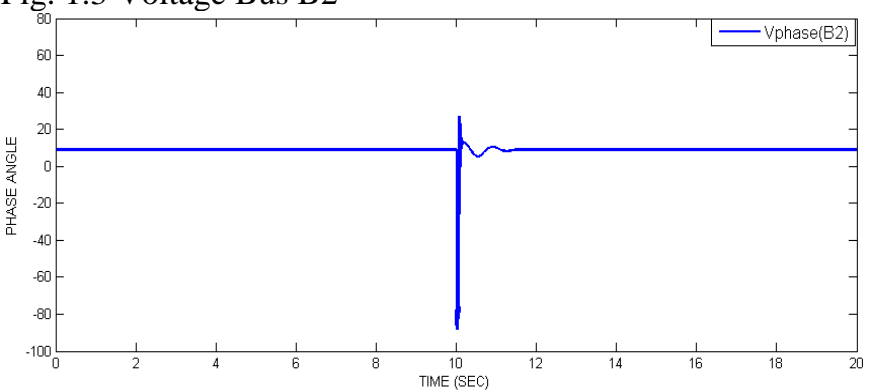

Fig.1.4 Phase Angle At Bus B2

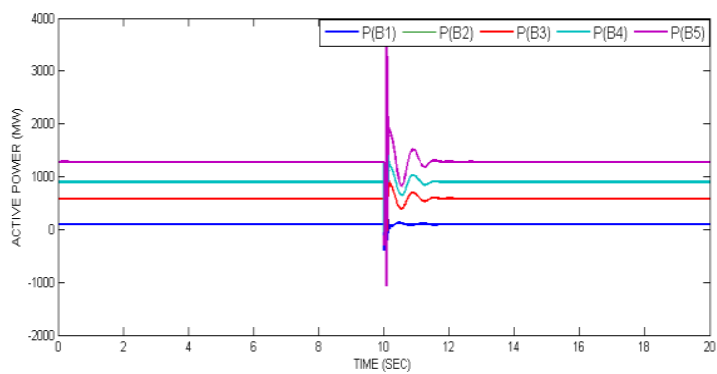

Fig. 1.5 Active Power At Different Bus

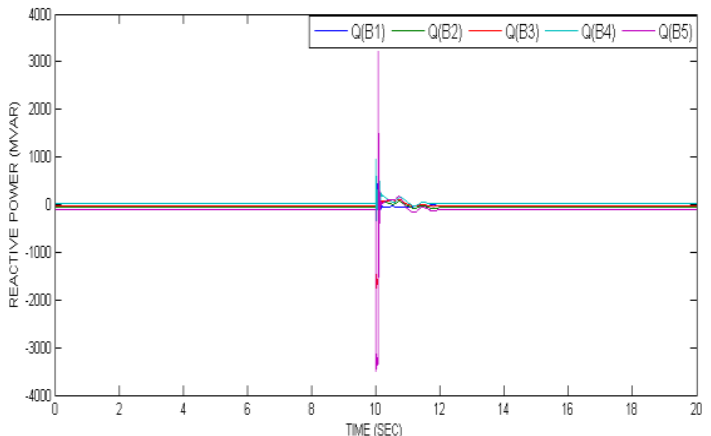

Fig. 1.6 Reactive Power At Different Bus

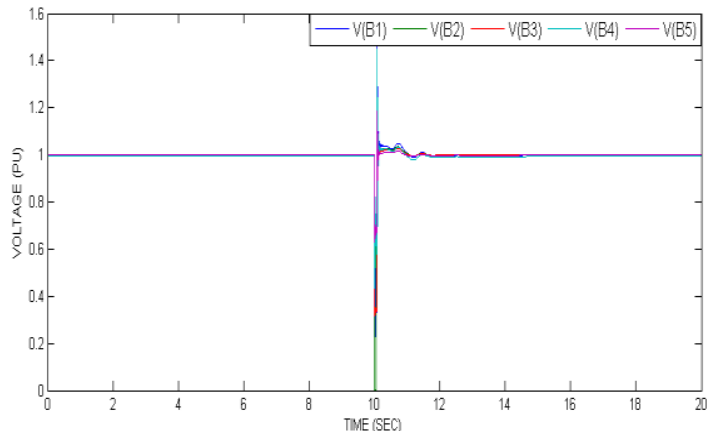

Fig. 1.7 Voltage At Different Bus 


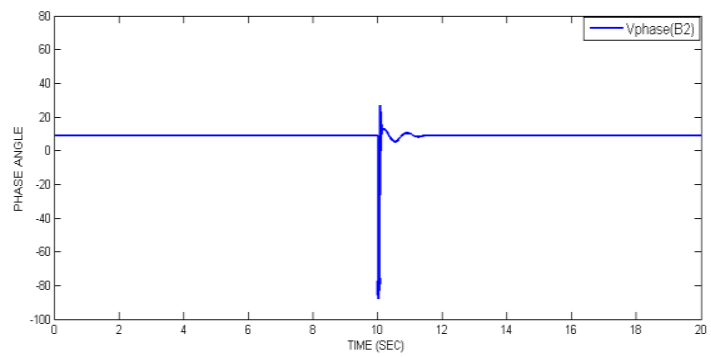

Fig. 1.8 Phase Angle At Different Buses

2) Using UPFC under 3-Phase to Ground Fault Condition
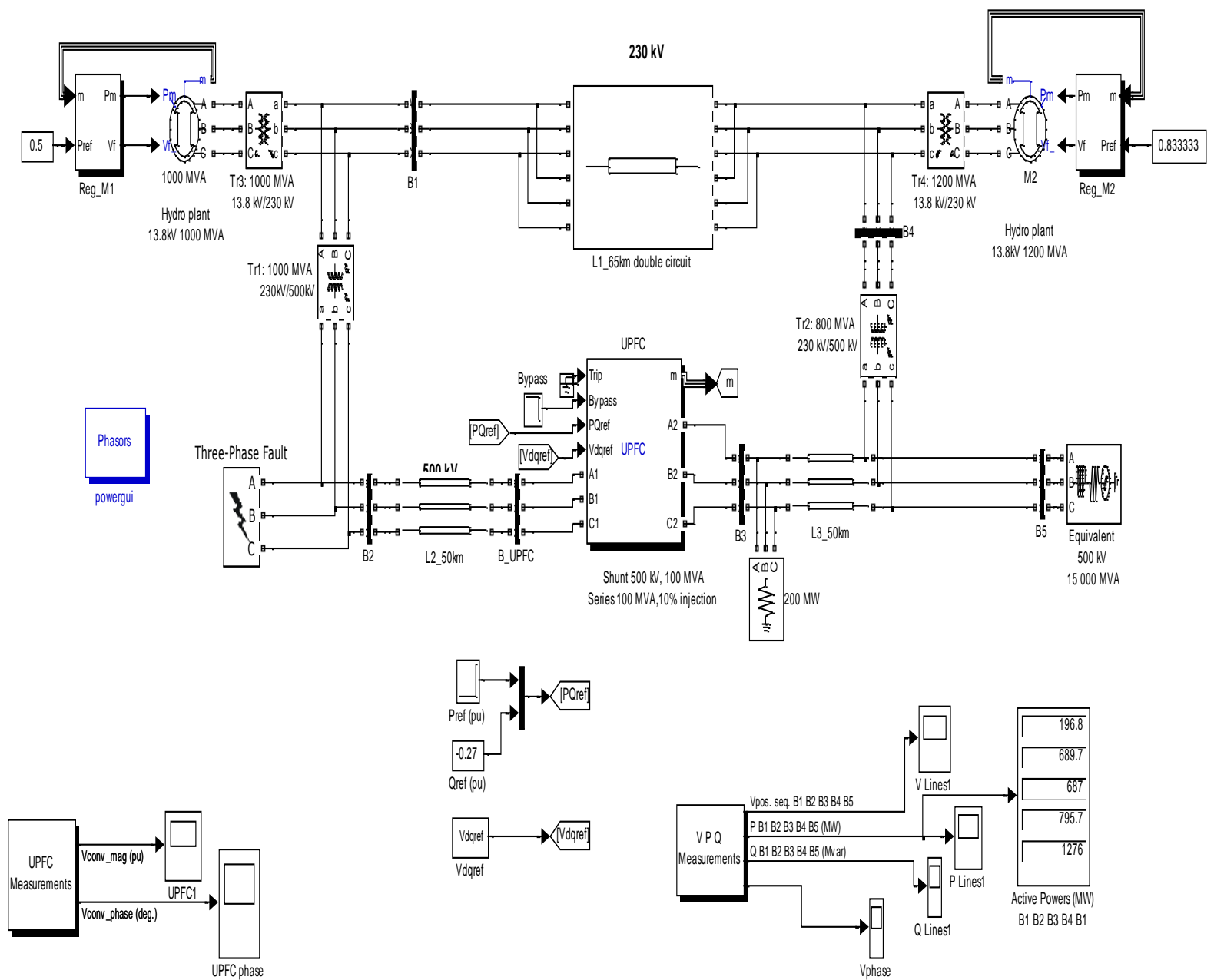

Fig: 2 Two Hydro Generating Stations Using UPFC under 3-Phase to Ground Fault Condition A three phase to ground fault is created at $\mathrm{t}=10 \mathrm{sec}$ for $0.08 \mathrm{sec}$ at bus 2 as shown in fig. 2 . The ratings of the various components used are given in appendix-B. The UPFC is made on at $\mathrm{t}=8 \mathrm{sec}$ and the power flow in the system goes from $5.87 \mathrm{pu}$ to $6.87 \mathrm{pu}$. The active power, reactive power, voltage and phase angle curves, voltage at UPFC with respect to time at all five buses (B1 B2 B3 B4 B5) are shown in fig. 2.1-2.10.

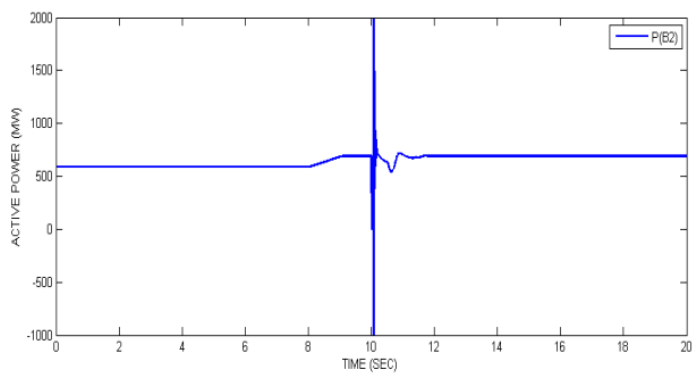

Fig 2.1 Active Power at Bus B2 


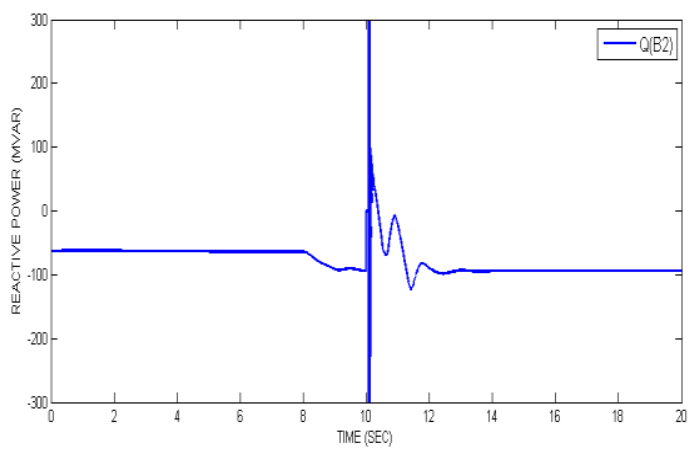

Fig. 2.2 Reactive Power at Bus B2

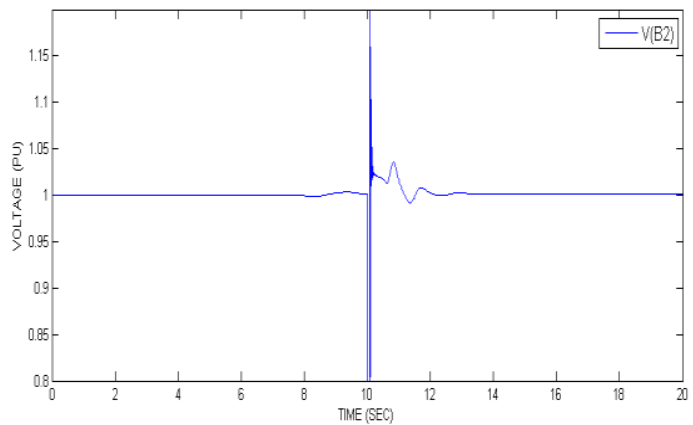

Fig. 2.3 Voltage at Bus B2

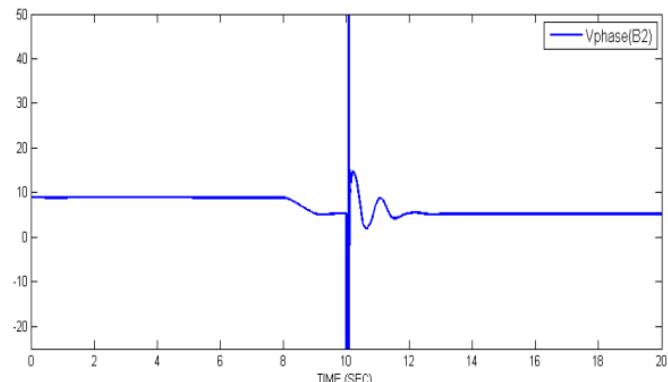

Fig. 2.4 Phase Angle at Bus B2

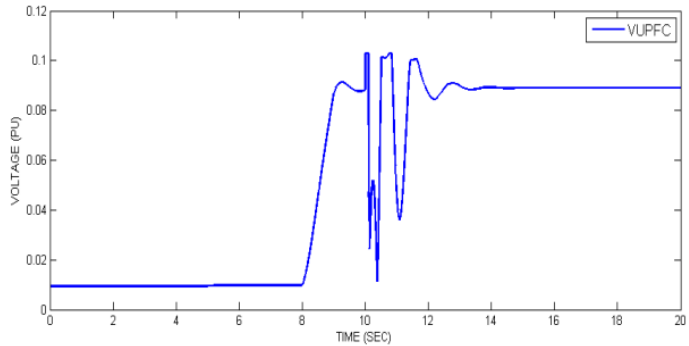

Fig. 2.5 Voltage at UPFC

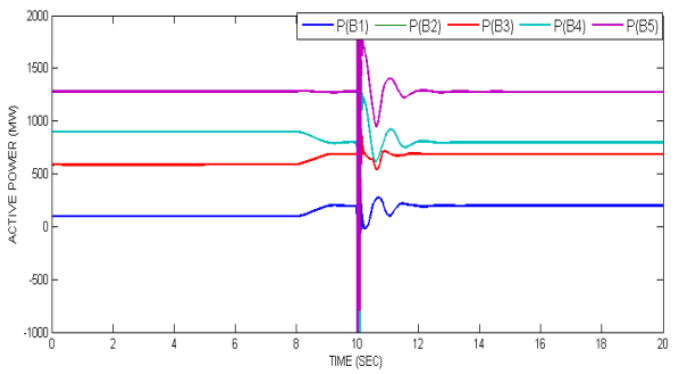

Fig. 2.6 Active Power at Different Bus 


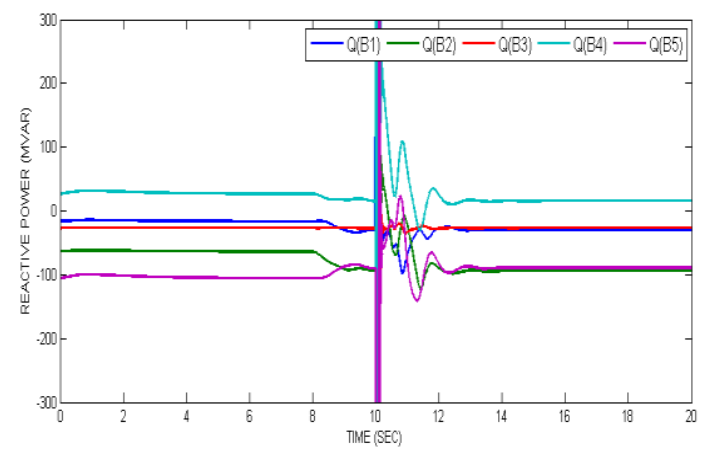

Fig. 2.7 Reactive Power at Different Bus

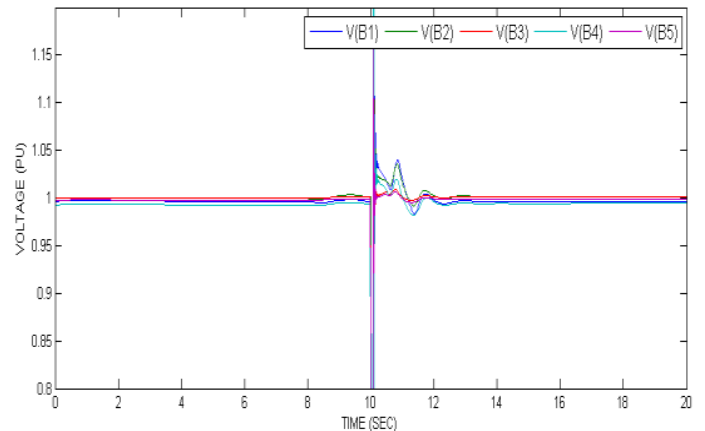

Fig. 2.8 Voltage at Different Bus

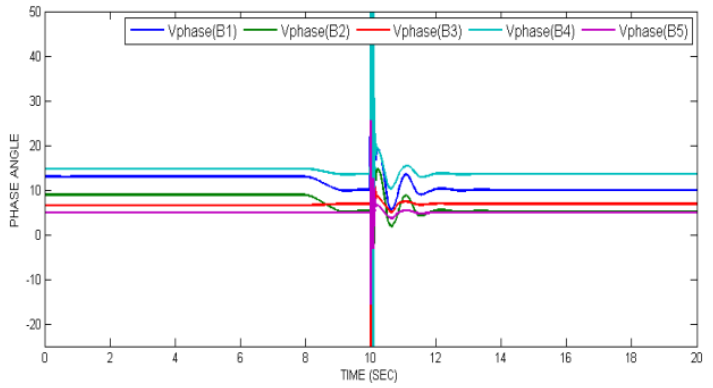

Fig. 2.9 Phase Angle at Different Buses

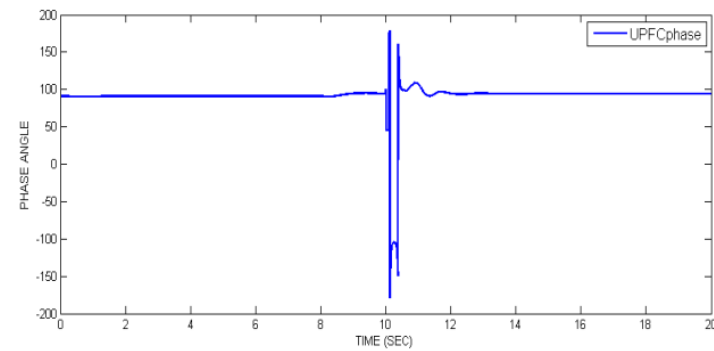

Fig. 2.10 Phase Angle at UPFC

\begin{tabular}{|l|c|c|}
\hline \multicolumn{3}{|c|}{ Active Power Flow (MW) } \\
\hline Buses & Without UPFC & With UPFC \\
\hline Bus 1 & 95.2 & 194.9 \\
\hline Bus 2 & 588.8 & 689.85 \\
\hline Bus 3 & 586.8 & 687.16 \\
\hline Bus 4 & 899 & 799.11 \\
\hline Bus 5 & 1279.5 & 1279.87 \\
\hline
\end{tabular}

It is observed that the time of clearing the fault is less when the system is provided with UPFC.

Here as can be seen from the table that the UPFC don't have much impact on the active power flow of the system but in case of fault, the oscillations produced in the system are much less in magnitude and also the time of clearing the fault is less when the system is provided with UPFC. 


\section{References}

[1]. N. G. Hingorani, L. Gyugyi, "Understanding FACTS: Concepts and Technology of Flexible AC Transmission Systems", New York: IEEE Press, 2000.

[2]. K. R. Padiyar, "FACTS Controllers in Power Transmission and Distribution" New Age International Publishers.

[3]. R. Mohan Mathur, Rajiv K. Verma," Thyristor Based FACTS Controller for Electrical Transmission System" Wiley-IEEE Press, 2002 .

[4]. H. Saadat, "Power Stability Analysis", TMH Publication Edition, 2002, pp. 460-526.

[5]. L. Gyugyi, T. R. Rietman, A. Edris, "The Unified Power flow Controller: A New Approach to Power Transmission Control" IEEE Transactions on Power Delivery, Vol. 10, No. 2, April 1995, pp. 1085-1097.

[6]. Vibhor Gupta, "Study and Effects of UPFC and its Control System for Power Flow Control and Voltage Injection in a Power System" International Journal of Engineering Science and Technology, Vol. 2(7), 2010, 2558-2566

[7]. Ejebe G., Irisari G., Mokhtari S., Obadina O., Ristanovic P., and Tong J., "Methods for Contingency Screening and Ranking for Voltage Stability Analysis of Power Systems," IEEE Trans. Power Systems, Vol. 11, no. 1, February 1 996, pp. 350-356

[8]. Gao B, Morison G., Kundur P., "Towards the Development of a Systematic Approach for Voltage Stability Assessment of LargeScale Power Systems," IEEE Trans. Power Systems, Vol. 11, no. 3, August. 1996, pp. 1314-1324.

[9]. M. R. Aghaebrahimi, M. Amiri, and M. Kamali Moghaddam, "A Short Circuit Study of an Induction Generator Wind Farm Considering Wind Speed Changes".

[10]. T. R. Mtshali, G. Coppez, S.Chowdhury, and S.P. Chowdhury, Member, "Simulation and Modeling of PV-Wind-Battery Hybrid Power System" IEEE 2011, pp.1-7.

[11]. S. M. Muyeen, M. H. Ali, R. Takahashi, T. Murata, and J. Tamura, "Stabilization of Wind Farms Connected with Multi Machine Power System by Using STATCOM" IEEE 2007, Paper ID 152, pp. 299-304

[12]. Ognedal R., Carlsen T., "Voltage Stability Condition in a Power Transmission System Calculated by Sensitivity Methods," IEEE Trans. Power Systems, Vol.5, no. 4, November 1990, pp. 1286-1293.

[13]. P. Kannan, S. Chenthur Pandian, C. Ramesh, M. Rajaram, "Voltage Sag Compensation of Thirty Bus System using Unified Power Flow Controller" European Journal of Scientific Research, ISSN 1450-216X Vol.51 No.3 (2011), pp.372-382

[14]. Padiyar K., Kulkarni A., "Control Design and Simulation of Unified Power Flow Controller," IEEE Trans. Power Delivery, Vol. 13, no. 4, October 1998, pp. 1348-1354

[15]. Papic I., Zunko P., Povh D., Weinhold M., "Basic Control of Unified Power Flow Controller," IEEE Trans. Power Systems, Vol. 12, no. 4, November 1997, pp. 1734-1739

[16]. Popovic D., Hiskens I., Hill D., "Stability Analysis of Induction Motor Networks," Electrical Power \& Energy Systems, Vol. 20, no. 7, 1998, pp. 475-487

[17]. Rahman M., Ahmed M., Gutman R., O'Keefe R., Nelson R., Bian J., "UPFC Application on the AEP System: Planning considerations," IEEE Trans. Power Systems, Vol. 12, no. 4, November 1997, pp. 1695-1701

[18]. Schauder C., Gyugyi L., Lund M., Hamai D., Rietman T., Torgerson D., Edris A., "Operation of the Unified Power Flow Controller (UPFC) Under Practical Constraints," IEEE Trans. Power Delivery, vol. 1 3, no. 2, April 1998, pp. 630-639

[19]. Vournas C., "Voltage Stability and Controllability Indices for Multi Machine Power Systems," IEEE Trans. Power Systems, Vol. 10, no. 3, August 1995, pp. 1183-1194 